IZA DP No. 4717

Mental Health and Working Conditions in European Countries

Elena Cottini

Claudio Lucifora

January 2010 


\title{
Mental Health and Working Conditions in European Countries
}

\author{
Elena Cottini \\ Università Cattolica Milan \\ and $C C P$ \\ Claudio Lucifora \\ Università Cattolica Milan, \\ ERMES and IZA
}

\section{Discussion Paper No. 4717 \\ January 2010}

IZA

P.O. Box 7240

53072 Bonn

Germany

Phone: +49-228-3894-0

Fax: +49-228-3894-180

E-mail: iza@iza.org

Any opinions expressed here are those of the author(s) and not those of IZA. Research published in this series may include views on policy, but the institute itself takes no institutional policy positions.

The Institute for the Study of Labor (IZA) in Bonn is a local and virtual international research center and a place of communication between science, politics and business. IZA is an independent nonprofit organization supported by Deutsche Post Foundation. The center is associated with the University of Bonn and offers a stimulating research environment through its international network, workshops and conferences, data service, project support, research visits and doctoral program. IZA engages in (i) original and internationally competitive research in all fields of labor economics, (ii) development of policy concepts, and (iii) dissemination of research results and concepts to the interested public.

IZA Discussion Papers often represent preliminary work and are circulated to encourage discussion. Citation of such a paper should account for its provisional character. A revised version may be available directly from the author. 


\section{ABSTRACT}

\section{Mental Health and Working Conditions in European Countries*}

Increased pressure for labour market flexibility and increasing demand over workers' performance have fostered the idea that working conditions, in most European countries, have progressively deteriorated with adverse effects on psychological well being and mental health. This paper investigates the links between contractual arrangements, working conditions and mental health using time-series cross-section data for 15 European countries. We use different waves of the European Working Conditions Survey $(1995,2000,2005)$ to document recent patterns in mental health at the workplace and to assess how these are related to various job attributes. We find substantial heterogeneity in mental health incidence at the workplace both across workers, as well as between countries. Given population heterogeneity in responses to mental health questions, we implement a methodology for differential reporting in ordered response models which allows for threshold shifts. We show that a set of workplace attributes, such as: working in shifts, performing complex and intensive tasks and having restricted job autonomy lead to a higher probability of reporting mental health problems. We also provide evidence of a positive causal effect of adverse overall working conditions on mental health distress. We show that labour market institutions, and health and safety regulations can explain a significant part of cross-country differences.

JEL Classification: $\quad$ C25, I10, J81, J28

Keywords: working conditions, mental health, health and safety regulation, labour market institutions

Corresponding author:

Elena Cottini

Istituto di Economia dell'Impresa e del Lavoro

Università Cattolica Milano

Via Necchi 5

I-20123 Milan

Italy

E-mail: elena.cottini@unicatt.it

\footnotetext{
* Previous versions of this paper have been presented at 2009 ESPE Conference (Seville), 2009 EALE Conference (Tallin), and in seminars at Universita Autonoma (Madrid), Università Cattolica (Milan) and Universite Paris2. We are grateful to Lorenzo Cappellari, Marco Francesconi, Guy Lacroix, Silvana Robone and seminar participants for their comments. Part of this paper was completed when C. Lucifora was visiting the School of Economics at UNSW in Australia. Financial support from Università Cattolica (D3.2 strategic projects) and "Health@Work" FP7 Network is gratefully acknowledged.
} 


\section{Introduction}

In recent decades industrialised countries have experienced substantial changes in the functioning of labour markets. Increasing competition in the product market, higher turbulence of aggregate demand and rapid technological progress have all contributed to increase pressure for higher labour flexibility. The latter has been pursued, at the aggregate level, by reforming labour market regulation and working arrangements i.e. reducing employment protection legislation and introducing non standard work arrangements - and, at the firm level, increasing demand over workers' performance i.e. with more demanding job tasks and lower workers' control. Indeed available evidence provides support to the idea that working conditions as well as subjective job well-being, in most European countries, have progressively deteriorated (Oecd, 2008). These changes, among other factors, are expected to impact on workers' health conditions and their overall well-being. Moreover, while the effect of working conditions on health was traditionally measured in terms of physical and environmental problems, the shift to service jobs and the increasing computerization of job tasks have significantly augmented the relevance of psychological and mental problems (Cappelli et al., 1997; Robone et al., 2008).

The European Mental Health Agenda of the European Union (EU) has recognised the prevalence and impact of mental health disorders in the workplace in EU countries: i.e. around $20 \%$ of the adult working population face some type of mental health problem at any given time. Also in the United States more than 40 million individuals in the workforce have some type of mental health disorder. The growing importance of mental health problems also shows in public health expenditure, since mental illness is among the most important contributors to the burden of disease and disability benefits in the industrialised world, as they constitute five of the 10 leading causes of disability (Marusic 2004).

The impact of mental health problems at the workplace, however, has serious consequences not only for individual well-being but also for firm's productivity. Mental health is likely to have significant externalities also on other workers, as well as the person with the illness. Employee performance, rates of illness, absenteeism, accidents and staff turnover are all strongly associated to employees' mental health status. Workers with better psychological well-being are generally more productive, less likely to suffer from illnesses limiting their working capacity and are less subject 
to sickness leave. In this respect, the burden of mental health disorders on health and productivity has long been underestimated. The economic cost of mental health problems, including treatment and the indirect cost of lost productivity and days off work, is estimated at more than 2 percent of GDP in the United Kingdom (Layard, 2005) and at approximately 1.7 percent of GDP in Canada (Stephens and Joubert, 2001). ${ }^{1}$

While aggregate patterns do not seem to show a generalised increase in mental health problems in the working-age population across Oecd countries, still there is evidence of growing strain in some countries and selected workforce groups, which may be concealed in the aggregate figures (Oecd, 2008). As far as differences across countries are concerned, it is notable to find that most European countries feature high in the ranking of mental health-working conditions deterioration, since they show both the largest increases in the share of workers reporting work-related mental problems as well as increases in the number of workers with increased stressful working conditions (Parent-Thirion et al., 2007). Several reasons might explain these patterns. Incentive schemes and shift to pay for productivity reward systems may have increased pressure for workers' performance at the workplace thus increasing stress, anxiety, irritability and other mood alterations. Also, flexible employment contracts may have increased individuals' perception of job insecurity and the likelihood of unemployment, thereby producing adverse effects on workers' psychological well-being. Differences in work and safety regulations at the workplace level, as well as labour market institutions - such as employment protection regulations, union coverage and provision for employment contract - may also play an important role in explaining cross-country patterns in mental health problems and psychological well-being.

Finally, observed heterogeneity across selected workforce groups in mental health and psychological well-being calls attention towards those workers who appear to be more vulnerable to the changing working conditions. In other words, changes in the demographic structure of the working-age population and increased female labour market participation have modified the standard view of the functioning of the labour market and the related health problems, from the traditional male 'breadwinner' worker, to female, young and older workers.

\footnotetext{
${ }^{1}$ In the United Kingdom, for example, 80 million days are lost every year due to mental illnesses, costing employers £1-2 billion each year. In the United States, estimates for national spending on depression alone are US\$ 30-40 billion, with an estimated 200 million days lost from work each year (The Mental Heath Foundation, 2000).
} 
We contribute to the existing literature in various ways. First, while a number of papers have documented for selected countries the effect of contractual provisions and working conditions on mental health and psychological well-being, also using panel data, to our knowledge there are no comprehensive studies which have investigated, using cross-country evidence, the links between employment provisions, workplace attributes and mental health. ${ }^{2}$ In this paper we use different waves of the European Working Conditions Survey to document recent patterns in mental health at the workplace across European countries, and to assess how working conditions - such as shifts, repetitive work, job autonomy, job intensity and job complexity - affect mental health. Second, in the light of the significant differences observed in mental health at work both between countries, as well as across labour market groups, we investigate the potential sources of these differences accounting for demographic characteristics, firm attributes, industry, occupational structure and the institutional context. While there is a lively debate among health economists and social scientists with respect to the validity of cross-country comparisons in self reported health, we do take a number of steps in this direction. In particular, given the concern that responses to mental health questions may differ across populations (i.e. due to past experience or cultural differences), in the empirical analysis we test the robustness of our estimates in various ways and implement a methodology for differential reporting in ordered response models which allows for threshold shifts. Next, since workers may sort across jobs according to their preferences and risk aversion, and firms may choose their health and safety expenditures, we present estimates of the causal effect of adverse working conditions on the probability of experiencing mental health problems accounting for different sources of endogeneity. Finally, we pay particular attention to the role of institutions, a much neglected issue. While most European countries have universal health coverage and a wide social safety net, they do differ in the degree of regulation of both health and safety at the workplace and labour market institutions. We show that the institutional environment is important to explain the differences in mental health distress across countries. The policy implications of mental health conditions and work quality are also quite relevant, since mental health problems and

\footnotetext{
${ }^{2}$ Notice that, while the use of case study and single country panel data is clearly a great advantage - as it often provides a wider range of health indicators and allows the possibility to control for (time invariant) unobserved factors - the lack of institutional variety can severely limit the possibility to generalise the results. Hence, there is a clear trade-off between accuracy of measurement and the cross-country dimension.
} 
poor psychological well-being have become an important source of public spending for public health and work related disability benefits in most European countries (Oecd, 2008). We discuss the main policy implication of our results in the final section.

The structure of the paper is as follows. Section 2 presents a brief review of the empirical literature. In section 3, a description of the data and some descriptive statistics are presented. The empirical strategy is outlined in Section 4, while results are reported and discussed in Section 5. Section 6 discusses the results comparing cross-country evidence and tries to bring in the role of institutions. The final section reports some concluding remarks.

\section{Review of the Literature}

While a large body of literature within the fields of applied psychology and occupational medicine has studied the relationship between mental health and the working environment, there are still relatively few contributions within the field of health economics that have addressed these issues. Epidemiologists and economists have proposed different hypotheses by which working conditions may affect individual mental health. On the one hand, different attributes of the job, which may be tangible (strength of manual work), psychological (stress, discrimination, conflicts at work) or contractual (fix-term job, job insecurity) are considered having a negative impact on psychological well-being and mental health. Moreover job attributes are likely to affect jointly, rather than independently, health outcomes in such a way that they may complement each other. However, the extent to which these features affect individual well-being, also depend on whether they are part of a contract, where pay is used to compensate for unfavourable working conditions (Rosen 1986); or they are the results of segmentation in the labour market where "good jobs", in one segment, provide a favourable working environment, job stability and career opportunities; while "bad jobs", in the other segment, are characterised by poor working conditions, job insecurity and low pay. In other words, it is not a job with demanding working conditions per se, that determines adverse effects on mental health and psychological well-being, rather it is the imbalance between job conditions and the reward structure which is assumed to be the driving factor.

Evidence from epidemiological studies provides support for the adverse health effects of job characteristics, such as psychological workload, stress and control over 
work (Kasl, 1998; Lundberg and Frankenhaeuser, 1999; Pikhart et al. 2004; Godin and Kittel, 2004). Another strand of research, in psychology, has focused on the health effects of new employment patterns, such as outsourcing and fixed-term employment, and found support for the hypothesis that job insecurity has adverse effects on psychological well-being (Aronsson and Goransson, 1999; Ferrie et al., 1999). Other studies, however, focusing either on specific groups (Vermeulen and Mustard, 2000) or using longitudinal data (Marchand et al., 2005) find weak evidence and question the robustness of the above findings .

In general, there is no broad consensus on empirical findings over the relationship between working conditions and mental health. The fact that most of the studies are based on single country cross-sectional data or on a case study makes even more difficult to compare and generalise results

Our paper is related to two different lines of research. The first relates to the literature that investigates the relationship between job insecurity and mental health. Empirical evidence typically has found that atypical employment - which includes both temporary and part-time employment schemes - does not appear to be associated with adverse health consequences for either men or women (Rodriguez, 2002; Bardasi and Francesconi, 2004); unemployed individuals conversely are found to suffer marked rise in anxiety, depression, loss of confidence, reduction in self-esteem and lower level of happiness even compared with individuals in low-paid employment (Theodossiou, 1998; Clark, 2003; Garcia Gomez and Lopez Nicolas 2005). ${ }^{3}$

The second, and less investigated, line of research looks more directly at the relationship between working conditions and mental distress. In general study in this area have shown that that jobs with tight working conditions - such as high demand, low control and low inter-personal support - are associated with worse health conditions at work (Warren et al., 2004; Datta Gupta and Kristensen, 2007). In this context, the study that is more closely related to our own, is Robone et al. (2008), which analyses the effects of contractual and working conditions on self-assessed health (SAH) and psychological well-being using twelve waves (1991/92 -2002/2003) of the British Household Panel Survey (BHPS). Their findings show that being unsatisfied with contractual and working conditions has a negative influence on the health of individuals. Llena Lozal (2008) and Datta Gupta et al. (2007) are, to the best of our knowledge,

\footnotetext{
${ }^{3}$ This seems to suggest that part of the association generally found between mental health and work is driven by the tendency of individuals to develop mental illness and to be non-employed.
} 
among the few studies that attempt cross country comparisons using longitudinal data for a selected number of countries. Results show that a favourable (perceived) work environment is conducive to better health conditions even after controlling for unobserved heterogeneity. Also, inactive individuals who obtain a non-standard job benefit less, in terms of mental health and psychological well-being, than those moving into standard employment arrangements.

\section{$3 \quad$ Data and Descriptive Evidence}

In this study we use three waves (1995, 2000 and 2005) of the European Working Conditions Survey (EWCS) to investigate the links between employment provisions at the workplace and mental health, in 15 European countries (i.e. Greece, Sweden, Italy, Finland, Luxemburg, France, Portugal, Belgium, Spain, Denmark, United Kingdom, Germany, Netherlands, Austria and Ireland). EWCS data provide detailed information on both work-related mental health problems, as well as job and workplace attributes. ${ }^{4}$ In particular, the questionnaire contains information on the physical and psychosocial environment, work organization and type of contract; as well as, on standard demographic characteristics (such as, gender, age, education, labor market status, income classes, etc.). Overall, after deleting missing observations, we ended up with a sample of approximately 15,000 workers per wave $(15,827$ in $1995 ; 21,983$ in 2000, and 14,601 in 2005).

The above features make the EWCS data a singular source of information to study the effects of working condition on health compared to the existing literature. First, the availability of a standard questionnaire across countries and waves, reduces considerably the risk of measurement error in morbidity indicators and job attributes due to different wording of questions and variables coding. This is a major advantage with respect to some of the studies reviewed above (Rodriguez, 2002; Ana Llena Lozal, 2008), which have pooled data from different surveys - i.e. as generally different countries use different definitions. Second, mental health indicators are based on workers' responses to a wide range of questions on whether their health is adversely affected by the type of work they do, the specific tasks that are performed as well as

\footnotetext{
${ }^{4}$ While, the number of questions and issues covered in the EWCS has expanded over time, still a core of questions have remained unchanged across the different waves, allowing a comparative study of the changes in working conditions and their effects.
} 
the work environment ${ }^{5}$. In this respect, detailed information on work-related mental health problems allows to construct a multi-dimensional indicator, based on selfassessed symptoms, which includes stress, sleeping problems, anxiety and irritability. ${ }^{6}$ Note that this set of questions can be considered as a first order approximation to the widely used DSM-IV classification for psychiatric diseases (Diagnostic and Statistical Manual of the American Psychiatric Association, 4th edition), as shown by Goldberg et al. (1997) who tested the validity of the mental distress score within the GHQ-12 (General Health Questionnaire) across 15 different countries. ${ }^{7}$ Third, the high level of detail on working conditions and work environment provides a way to control for confounding factors which may affect the relationship between work and psychological well-being at the workplace. Finally, the cross section-time series structure of the data allows the possibility to control for aggregate unobserved factors which may affect both health and work environment across countries and over time. In practice, this means that our empirical strategy includes country and year fixed effects in all estimations. Country effects capture stable differences between countries in both mental health and working conditions (including the way both are measured), while year fixed effects capture the influence of common shocks that affect mental health at the same time (i.e. changes EU standard for mental health coverage and treatment, as well as EU directives on working conditions and safety standards).

Additionally, we complemented the EWCS data with information on labour market institutions and business cycle indicators (i.e. unemployment), as well as with indicators of safety and health regulations for the EU 15 countries over the period $1995-2005 .^{8}$

\footnotetext{
${ }^{5}$ Our measure of health is the standard individual's self-assessed health ( $\left.\mathrm{SAH}\right)$, which has been shown to be an excellent predictor of a number of health and economic outcomes (see, Idler and Benyamini, 1997; Burströmm and Fredlund, 2001).

${ }^{6}$ This multidimensional feature of the mental health indicator is also major advantage as compared to studies that can only use comprehensive measures of mental health such as, Oswald and $\mathrm{Wu}$ (2009).

${ }^{7}$ Gravelle and Sutton (2006) present an interesting discussion of self-assessed health indicators and how they are used in empirical studies.

${ }^{8}$ The source of the labour market data is the OECD 'Labour Market Institution Database' (LMID) available online. The indicator of safety and health regulation is constructed by the authors following ILO ratification (i.e. ILO Directives Archives: ILODA) implemented in each EU 15 country over the period 1995-2005.
} 


\subsection{Definition and Measurement}

Our definition of mental health problems focuses on four types of indicators which capture a series of emotional and mood-related problems that are reported by the worker as being work-related. In particular, we measure morbidity using a set of selfassessed responses to the following questions present in each wave of EWCS. "Does your work affect your health, or not?" If yes, "how does it affect your health?" (i) Stress (stress); (ii) sleeping problems (sleep); (iii) anxiety (anxiet); (iv) irritability (irrit). ${ }^{9}$ Out of the above responses we specified a set of dummies (in parentheses above), that take value 1 if the worker mentions the problem and 0 if the problem was not mentioned. For example individuals were classified as reporting stress problems if they replied that their job affected in some way their health and choose stress as one of the reasons among a checklist of several options. As a measure of the intensity of the mental health distress reported, we use the four indicators described above to construct a composite index (mentalh) obtained summing up all the preceding dummy variables. This goes in the direction of medical studies suggesting that more serious mental health problems usually involve more than one symptom (Rugulies et al., 2008). Hence, we anticipate that the more (or less) an individual reports problems in her or his mental health, the greater (smaller) is likely to be the distress originating from working conditions. ${ }^{10}$ However, in order to ensure that the results are not mainly driven by the sub-sample of people who report the highest levels of mental health distress, we also construct an indicator that takes value 1 if at least one health problem has been mentioned, and 0 otherwise (mentalh-dum).

For what it concerns the effects of working conditions on mental health, to facilitate comparison with previous studies, we use several aspects of the working environment which have been shown to be relevant to describe working conditions at the firm in terms of intensity and complexity of job tasks, workers' job autonomy, and other job amenities (see Bockermann and Illmakunnas, 2007; Oecd, 2008). In practice, the following seven indicators have been selected, which are constructed out of

\footnotetext{
${ }^{9}$ The range of answers contains also a set of physical problems (such as hearing, vision, skin and resporatory problems; backache, stomachache, muscular pain, heart disease and injury ), which we do not consider as they do not constitute the focus of our paper.

${ }^{10}$ There are various options available to construct a composite indicator. Here we have chosen the simplest and direct approach, which gives equal weight to each of the factors contributing to individual's mental health distress. Some experimentation using the first factor with principal component analysis gave very similar results. Correlation between the composite indicator obtained summing up the dummies and the one obtained by principal component analysis is 0.95 .
} 
a seven-point scale in which the highest category corresponds to worker's perception that a given work attribute is "very much" an adverse factor at the workplace (i.e. name of the variables is in parentheses below). High work intensity (highwint) takes value 1 if the job includes working at very high speed and tight deadlines from half of the time to almost all the time (0 otherwise). Number of working hours (whours) takes value 1 if the employee works more than 40 hours per week. Repetitive work (repwo) takes value 1 if the job involves short repetitive tasks of at least 10 minutes. Similarly low job autonomy (lowJaut), work that involves complex tasks (compltask), working in shifts (shift), and having no assistance from colleagues (noasscolleg), all take value 1 if the conditions are regarded as a significant disutility at work by the individual.

As a summary measure of the overall working conditions reported by the worker, we use a synthetic index of job attributes (WCtot), by summing up all dummy variables which have been reported to affect workers disutility at the workplace. In other words, all the factors considered above do contribute to determine the quality of work, also beyond the workplace, particularly linking and balancing work and life and psychological well-being ${ }^{11}$.

Additionally, we consider a discrimination indicator (discrimtot) that takes value 1 if the individual has experienced discrimination at the workplace of any kind (i.e. gender, sexual orientation, ethnic, religious and disability discrimination), and a relational aspect on the job that indicates whether the boss is a woman (bossw), which has been shown to be relevant in psychological studies (Schieman et al., 2006: Eagly and Johannesen-Schmidt, 2001). To account for extra payments systems we construct an indicator that is the sum of 4 dummy variables that respectively take value 1 if the remuneration includes piece rate/productivity payment or payment for overtime or payment for sunday working hours or compensation for poor working conditions (ExPay). The variable concerned with contractual condition of the job (permanent) is constructed from the following question: "What kind of employment contract do you have?", takes value 1 if the the answer is "an indefinite term contract" (0 otherwise).

We then have a set of additional controls for individual characteristics and workplace attributes. As to individual characteristics, we control for gender (female), age dummies (age1-age 4$)^{12}$, marital status for married or living in couple (spousepart),

\footnotetext{
${ }^{11}$ This is likely to be relevant in particular for women, where concilation between work and life is more difficult (Bratti, Del Bono,Vuri, 2005 ).

${ }^{12}$ We allow for a piece-wise relationship with health and psychological well-being, to capture the
} 
education based on ISCED codes $(e d u c 1-e d u c 4)^{13}$, and presence of children in the household (child). We further control for individual income using the distribution of income in quartiles (inc1-inc4) ${ }^{14}$. The set of workplace attributes included in the estimations are dummies for firm's size (fize1-fsize5), industry dummies (ind1-ind11) and occupational dummies (occ1-occ10). We further control for country fixed effects with a set of dummy variables identifying the country of interview of the worker (country1-country15).

In order to capture the level of safety regulations at the workplace, in each country, we construct an index based on ILO ratifications ( $I L O_{-}$index) by each country for the period 1995-2005. The ratifications we consider are of two types: the first provides general guidelines on occupational health and safety services, the second regulates the protection of workers against specific hazards experienced at the workplace. A more detailed description of this index and a definition of the variables used is given in the Appendix (Table A1).

\subsection{Stylised Facts}

In Figure 1, we compare two alternative measures of work-related mental health distress across 15 European countries. The first, provides an overall measure of the incidence of mental health distress $(N S)$ across countries (i.e. at least one problem reported, as in our mentalh-dum indicator), the second focuses more on the intensity (or gravity) of mental distress (pmore2), reporting the distribution for cumulating more than two mental health problems. When we consider the overall measure, we detect significant differences across countries. In particular, the ranking of countries shows Greece, Sweden and Italy at the top of the chart, while Ireland, Austria and The Netherlands are located at the opposite end. When we focus on the intensity

existence of non-linearities

${ }^{13}$ Note that ISCED codes for education are not available in the EWCS for year 2000. Hence, education observations for that year are set to missing. Some experimentation was performed by imputing the education levels from pooled 1995-2005 regressions, results however did not change substantially.

${ }^{14}$ In the EWCS, income was measured by asking the respondents to position their usual monthly earnings in their main paid job on a 4-point scale corresponding to the 4 income quartiles in each country. Unfortunatly this variable is not available in first wave of the survey. Therefore we use personal and firm characteristics to infer income for individuals surveyed in 1995. This procedure is called Two stage Two sample approach (TS2SLS) and it is a special case of "Two sample Instrumental variable" (TSIV) technique used by Angrist and Krueger (1992) and Arellano and Meghir (1992). 


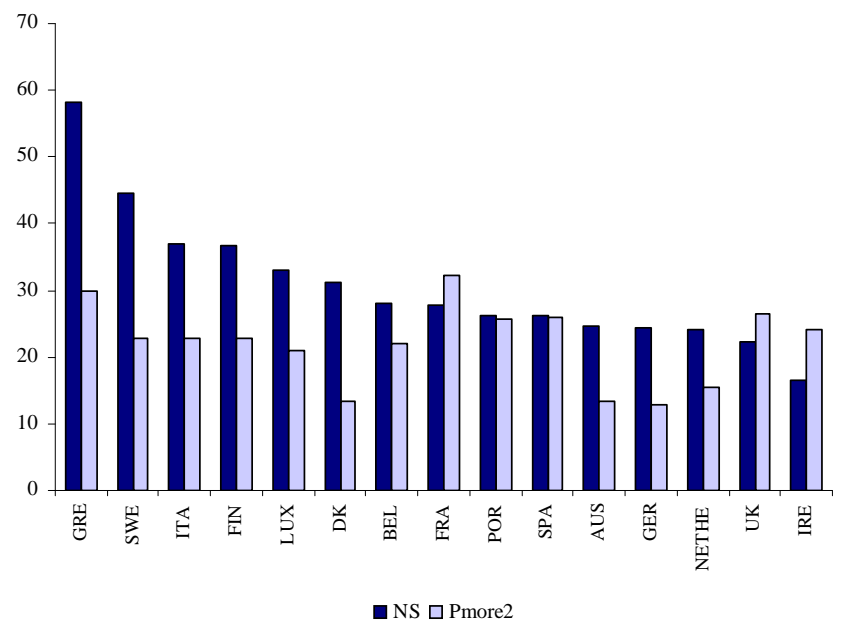

Figure 1: Mental Health distress across countries

measure, we find a much lower dispersion across countries and no evidence that the countries in which incidence is larger are also the ones where mental health problems at the workplace are more serious. Since these indicators are simple (unconditional) averages, as a further check, we also computed the ranking retaining the estimated country fixed effects after controlling for a set of workforce demographic characteristics. The ranking we obtain in this way is essentially unchanged, while some of the differences appear even larger (i.e. Greece). We finally compared our ranking with the GHQ-N6 index of mental distress reported in Blanchflower and Oswald (2008, table B1): the correlation between the two indicators is 0.47 .

To get a rough idea of the relationship between mental health distress and working condition, in Figure 2 we plot the two summary indicators (mentalh and WCtot), computed as previously described, across countries. The resulting pattern suggests a positive correlation $(r h o=0.37$ ) between the mean incidence of mental health problems and the overall toughness of working conditions (i.e. which is still positive even dropping Greece). In other words, countries where working conditions are reported to be harder are also those experiencing a higher incidence of mental health distress. While this stylised fact is indicative of the relationship that we are trying to uncover, it should be stressed that this simple (unconditional) correlation may be completely spurious. Indeed, many compositional effects as well as country-specific factors, quite independently of any causal effect of working conditions on health (or viceversa), 


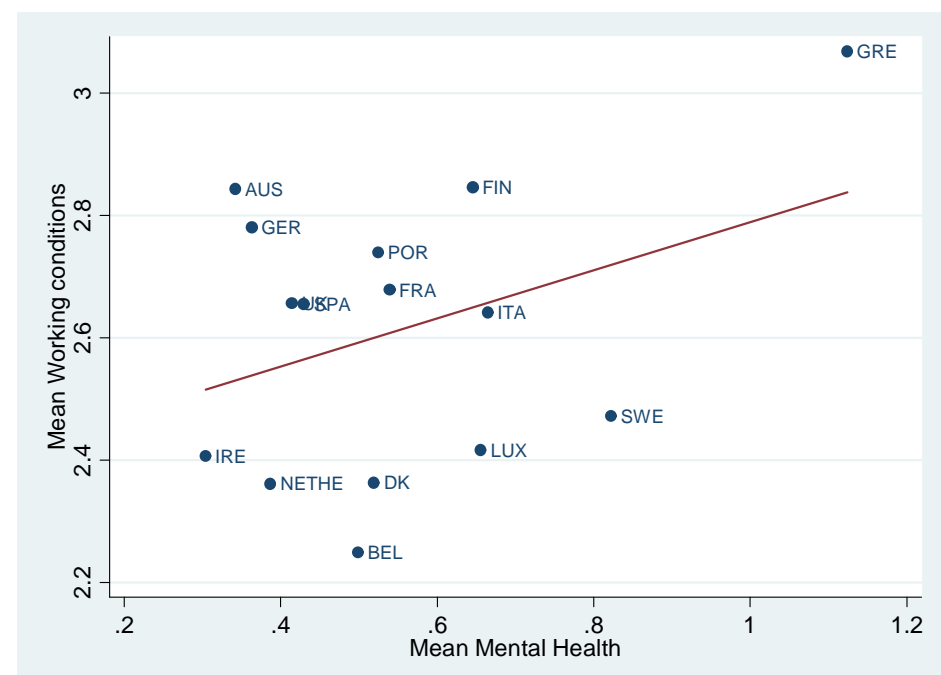

Figure 2: Working conditions and mental health distress across countries

could drive the observed association between working conditions and mental health.

Finally, in Table 1 we report with greater detail the distribution of employees - by gender, sector (public versus private) and type of occupation (white versus blue collar) - according to either the intensity of mental health problems or the type of mental health distress reported. Around 16 percent of workers report at least one mental health problem connected to their job: males report a slightly higher morbidity with respect to females, while no significant differences appear between the other groups. Focusing on specific mental problems, we find that "stress" at work is the most common problem reported by employees (42 percent) followed by irritability (36.4 percent). In particular, stress at work seems to be prevalent in the private sector (44 percent) as opposed to the public sector (38 percent), while white collar employees seem to be more likely to suffer from irritability ( 36.8 vs 35.7 percent) and sleeping problems (13.3 vs 12.8 percent) as compared to blue collars.

\section{Empirical Strategy}

Our empirical strategy is based on a cross-section time-series analysis, where we regress and indicator of work-related mental health morbidity on a set of working conditions dummy variables, a vector of demographic characteristics and a wide range 
Table 1: Distribution of mental health distress, (percentages)

\begin{tabular}{cccccccc}
\hline mentalh & Total & Female & Male & Public & Private & White & Blue \\
\hline 0 & 68.78 & 69.34 & 68.3 & 63.63 & 70.69 & 67.3 & 71.43 \\
1 & 16.74 & 15.86 & 17.49 & 17.93 & 16.3 & 17.01 & 16.25 \\
2 & 8.08 & 7.98 & 8.16 & 9.87 & 7.41 & 8.63 & 7.1 \\
3 & 4.27 & 4.52 & 4.06 & 5.64 & 3.76 & 4.69 & 3.52 \\
4 & 2.14 & 2.3 & 2.0 & 2.93 & 1.84 & 2.38 & 1.71 \\
\hline Nobs & 51,911 & 23,763 & 28,148 & 14,068 & 37,843 & 32,954 & 18,627 \\
\hline \multicolumn{7}{c}{ Single mental health items } \\
\hline stress & 42.27 & 41.97 & 42.97 & 38.33 & 44.07 & 42.0 & 42.91 \\
irritability & 36.46 & 36.99 & 36.02 & 39.53 & 35.06 & 36.83 & 35.68 \\
sleeping problems & 12.96 & 12.8 & 13.1 & 14.44 & 12.29 & 12.78 & 13.32 \\
anxiety & 8.3 & 8.23 & 8.36 & 7.7 & 8.58 & 8.39 & 8.09 \\
\hline Nobs & 19,260 & 10,550 & 8,710 & 6,026 & 13,234 & 12,586 & 6,530 \\
\hline \hline
\end{tabular}

Note: 'White collar' includes: legislators, professionals, technicians, clerks, service workers and sales workers; 'Blue collar' includes: skilled agriculture and fishery workers, craft and trade workers, plant and machine operators and elementary occupations

of firm and job attributes. The model is specified as follows:

$$
\operatorname{Pr}\left(M H_{i j t}=j \mid W C, X\right)=\Phi\left(\alpha+\gamma W C_{i j t}+\beta D_{i j t}+W A_{i j t}+J C_{i j t}+c_{j}+t_{t}+\varepsilon_{i j t}\right)
$$

where the left hand side variable $M H_{i j t}$ represents the realization of a latent mental health indicator $\left(M H^{*}\right)$, as previously described, for individual $i$, in country $j$ at time $t$. $W C_{i j t}$ is a set of variables describing individuals' working conditions in the current job. $D_{i j t}$ is a vector of demographic characteristics (i.e. gender, age, level of education, presence of children in the household and civil status), $W A_{i j t}$ is a vector of workplace attributes (i.e. firm size, industry) and $J C_{i j t}$ accounts for job characteristics (i.e. occupation, type of contract, labour income, extra payments, discrimination at the workplace, boss is a woman). All the regressions include country $\left(c_{j}\right)$ and time dummies $\left(t_{t}\right)$. We first estimate equation (1) by a simple probit using the mentalh-dum as dependent variable (see Table 2). Next, we exploit the categorical nature of the mentalh variable and estimate an ordered probit (see Table 3). Results are reported for the entire sample - pooling countries and time periods - and, given the importance of the gender dimension (see Artazcoz et al., 2005; Vermeulen et al., 2000), also separately for males and females. For ease of interpretation, we always report 
partial effects. As previously discussed, to account for the fact that ordered responses on health questions may differ across populations and that reporting heterogeneity may invalidate our results, we also estimate a different specification in which the estimated threshold are allowed to vary according to selected personal characteristics or an index of job satisfaction. ${ }^{15}$ The rationale for the above is that different groups may have a different perception of what is to be considered, for example, "stress" at work; or that employees who are not satisfied with their job may report mental health problems regardless of their true level of mental health (Groot, 2001; Kerkhofs and Lindeboom, 1995). Finally, we report a number of sensitivity analyses performed to assess the robustness of our results (Table 4 and Table5).

\section{Results}

Table 2 reports the first set of results obtained estimating equation (1) with a simple probit. In columns (1) to (2) we present estimates with and without income and extra pay controls, while in columns 3 and 4 we show estimates for female and male separately. Our result show that adverse working conditions are positively associated with employees reporting mental health distress at work and the estimated partial effects are statistically significant in all specifications (for almost all indicators). In other words, the partial effect on the probability of reporting (at least) one mental health problem for workers that perform repetitive work (repwo) is 3.4 (column 1), meaning that repetitive work increases the probability of suffering from (at least one) health problems by 3.4 percentage points. The lack of assistance from colleagues (noasscolleg) shows the wrong sign but it is not statistically significant (except in column 6 for men). Comparing the relative impact of the different working conditions attributes, performing a task that requires high work intensity (highwint) shows the largest effect (over 12 percent). In terms of significance and magnitude of the working conditions indicators, results do not change when we augment our previous

\footnotetext{
${ }^{15}$ One problem with self-reported measures of health and working conditions is that, since they are both self-assessed, when the scale of reference varies systematically with measured (or unmeasured) characteristics, regressing one subjective variable on another subjective variable may bias the estimated coefficients upward (i.e. due to common error components). To account for this, as discussed in a later section, we implement an estimation procedure which allows estimated cutoffs to vary according to measured characteristics. An alternative route is to use anchoring vignette as in Rice et al. (2009). The vignette approach however is very demanding in terms of data collection and it is hardly a feasible option when using cross-country surveys.
} 
Table 2: Mental health and working conditions, (probit estimates, ME)

\begin{tabular}{|c|c|c|c|c|}
\hline \multirow[b]{2}{*}{ PROBIT } & \multicolumn{2}{|c|}{ All } & \multirow{2}{*}{$\begin{array}{c}\text { Female } \\
(3)\end{array}$} & \multirow{2}{*}{$\begin{array}{l}\text { Male } \\
(4)\end{array}$} \\
\hline & (1) & $(2)$ & & \\
\hline female & $\begin{array}{l}.02^{* * *} \\
(.008)\end{array}$ & $\begin{array}{l}.046^{* * *} \\
(.0 .1)\end{array}$ & & \\
\hline agecl2 & $\begin{array}{c}.062^{* * *} \\
(.013)\end{array}$ & $\begin{array}{c}.059^{* * * *} \\
(.014)\end{array}$ & $\begin{array}{l}.092^{* * * *} \\
(.021)\end{array}$ & $\begin{array}{l}.038^{* *} \\
(.019)\end{array}$ \\
\hline agecl3 & $\begin{array}{c}.092^{* * *} \\
.014)\end{array}$ & $\begin{array}{c}.078^{* * *} \\
(.015\end{array}$ & $\begin{array}{c}.097^{* * *} \\
(.022)\end{array}$ & $\begin{array}{c}.067^{* * *} \\
(.021)\end{array}$ \\
\hline agecl4 & $\begin{array}{c}.071^{* * * *} \\
(.014)\end{array}$ & $\begin{array}{c}.059^{* * * *} \\
(.016)\end{array}$ & $\begin{array}{l}.104^{* * *} \\
(.022)\end{array}$ & $\begin{array}{l}.029 \\
.021)\end{array}$ \\
\hline educmid & $\begin{array}{c}-.027^{* *} \\
(.012)\end{array}$ & $\begin{array}{c}-.032^{* *} \\
(.013)\end{array}$ & $\begin{array}{c}-.045^{* *} \\
(.018)\end{array}$ & $\begin{array}{l}-.019 \\
(.017)\end{array}$ \\
\hline educhigh & $\begin{array}{c}-.027^{* *} \\
(.013)\end{array}$ & $\begin{array}{c}-.042^{* * *} \\
(.013)\end{array}$ & $\begin{array}{c}-.059^{* * *} \\
(.020)\end{array}$ & $\begin{array}{l}-.019 \\
(.021)\end{array}$ \\
\hline child & $\begin{array}{l}-.001 \\
(.008)\end{array}$ & $\begin{array}{l}-.0004 \\
(.009)\end{array}$ & $\begin{array}{l}.0006 \\
(.013)\end{array}$ & $\begin{array}{l}-.0002 \\
(.012)\end{array}$ \\
\hline spousepart & $\begin{array}{c}-.017^{* *} \\
(.009)\end{array}$ & $\begin{array}{c}-.022^{* *} \\
(.009)\end{array}$ & $\begin{array}{l}-.0016 \\
(.013)\end{array}$ & $\begin{array}{l}-.0216 \\
(.014)\end{array}$ \\
\hline discrimtot & $\begin{array}{l}.212^{* * *} \\
(.017)\end{array}$ & $\begin{array}{c}.206^{* * *} \\
(.018)\end{array}$ & $\begin{array}{l}.24^{* * *} \\
(.025)\end{array}$ & $\begin{array}{c}.179^{* * *} \\
(.026)\end{array}$ \\
\hline bossw & $\begin{array}{l}.006 \\
.009)\end{array}$ & $\begin{array}{l}.004 \\
(.01)\end{array}$ & $\begin{array}{l}.002 \\
(.012)\end{array}$ & $\begin{array}{l}.0021 \\
(.019)\end{array}$ \\
\hline permanent & $\begin{array}{l}.017^{*} \\
(.009)\end{array}$ & .011 & $\begin{array}{l}.0011 \\
(.015)\end{array}$ & $\begin{array}{l}.011 \\
(.015)\end{array}$ \\
\hline repwo & $\begin{array}{c}.034^{* * *} \\
.007)\end{array}$ & $\begin{array}{c}.037^{* * *} \\
.009)\end{array}$ & $\begin{array}{c}.055^{* * *} \\
(.012)\end{array}$ & $\begin{array}{l}.023^{* *} \\
(.011)\end{array}$ \\
\hline shift & $\begin{array}{c}.077^{* * *} \\
(.01)\end{array}$ & $\begin{array}{c}.079^{* * *} \\
(.011)\end{array}$ & $\begin{array}{c}.081^{* * *} \\
(.017)\end{array}$ & $\begin{array}{c}.081^{* * *} \\
(.016)\end{array}$ \\
\hline highwint & $\begin{array}{c}.124^{* * *} \\
(.007)\end{array}$ & $\begin{array}{c}.128^{* * * *} \\
(.008)\end{array}$ & $\begin{array}{c}.129^{* * *} \\
(.012)\end{array}$ & $\begin{array}{c}.127^{* * *} \\
(.011)\end{array}$ \\
\hline noasscolleg & $\begin{array}{c}-.022^{* *} \\
(.009)\end{array}$ & $\begin{array}{c}-.022^{* *} \\
(.011)\end{array}$ & $\begin{array}{l}-.007 \\
(.015)\end{array}$ & $\begin{array}{c}-.037^{* *} \\
(.015)\end{array}$ \\
\hline lowJaut & $\begin{array}{c}.026^{* * *} \\
.007)\end{array}$ & $\begin{array}{c}.024^{* * *} \\
.008)\end{array}$ & $\begin{array}{l}.007 \\
(.012)\end{array}$ & $\begin{array}{c}.041^{* * *} \\
(.012)\end{array}$ \\
\hline compltask & $\begin{array}{c}.071^{* * *} \\
(.008)\end{array}$ & $\begin{array}{c}.065^{* * *} \\
(.008)\end{array}$ & $\begin{array}{c}.064^{* * *} \\
(.013)\end{array}$ & $\begin{array}{c}.069^{* * *} \\
(.011)\end{array}$ \\
\hline whours & $\begin{array}{l}.10^{* * *} \\
(.01)\end{array}$ & $\begin{array}{c}.096^{* * *} \\
(.008)\end{array}$ & $\begin{array}{l}.062^{* * *} \\
(.021)\end{array}$ & $\begin{array}{c}.109^{* * *} \\
(.013)\end{array}$ \\
\hline ExPay & & $\begin{array}{l}.011^{* *} \\
(.005)\end{array}$ & $\begin{array}{c}.010^{* * *} \\
(.008)\end{array}$ & $\begin{array}{l}.010^{*} \\
(.006)\end{array}$ \\
\hline Sector and Region & $\sqrt{ }$ & $\sqrt{ }$ & $\sqrt{ }$ & $\sqrt{ }$ \\
\hline Year & $\sqrt{ }$ & $\sqrt{ }$ & $\sqrt{ }$ & $\sqrt{ }$ \\
\hline Firm size occupation & $\sqrt{ }$ & $\sqrt{ }$ & $\sqrt{ }$ & $\sqrt{ }$ \\
\hline Income & & $\sqrt{ }$ & $\sqrt{ }$ & $\sqrt{ }$ \\
\hline pseudo- $\mathrm{R}^{2}$ & .102 & .103 & .126 & .102 \\
\hline Nobs & 40,306 & 34,652 & 16,843 & 17,809 \\
\hline $\begin{array}{l}\text { Note:Marginal effects } \\
1 \%, * * 5 \%, * 10 \% \text {; robu } \\
\text { ence group is characte } \\
16-25 \text {, no educational } \\
\text { dependent children, e1 } \\
\text { try, unskilled occupat } \\
\text { gium, work less than } \\
\text { income distribution. }\end{array}$ & $\begin{array}{l}\text { are repo } \\
\text { st standa } \\
\text { ised by th } \\
\text { qualificat } \\
\text { aployed in } \\
\text { on, privat } \\
0 \text { hours } \\
\text { r coding }\end{array}$ & $\begin{array}{l}\text { ed. Sigr } \\
\text { errors in } \\
\text { following } \\
\text { n, not } \mathrm{m} \\
\text { the agricu } \\
\text { sector, sn } \\
\text { f week, } \mathrm{n} \\
\text { all varial }\end{array}$ & $\begin{array}{l}\text { ficance le } \\
\text { parenthest } \\
\text { ttributes: } \\
\text { ried/coha } \\
\text { ural/prim } \\
\text { all firm si } \\
\text { in first } \\
\text { es see Tab }\end{array}$ & $\begin{array}{l}\text { ls: } * * * \\
\text { Refer- } \\
\text { nale, age } \\
\text { iting, no } \\
\text { y indus- } \\
\text {, in Bel- } \\
\text { antile of } \\
\text { A1 }\end{array}$ \\
\hline
\end{tabular}


specification with an indicator for extra payments (reported in column 2). These results are essentially unchanged when we estimate the model separately by gender (columns 3 and 4). In line with most of the literature, adverse working conditions are shown to have a positive and sizeable association with mental health problems and psychological distress (Siegrist, 1996; Robone et al.,2008).

The impact of demographic characteristics is also interesting. The female dummy is positive and statistically significant suggesting that women exhibit higher rates of minor mental health morbidity and depression as compared to men (Madden, 2008). Married individuals, as compared to non-married, are found to be in better mental health conditions (column 1-2), although this result is not robust when we estimate the model separately by gender (column 3 and 4$)^{16}$. In general higher education is significantly associated with better mental health status (Leigh et al., 2009), as shown by the negative and statistically significant marginal effect on the high education variable. In our preferred specification (column 2), the marginal effect of reporting at least one health problem for workers with higher education is -3.9 percentage points. Workers with a permanent contract, compared to those with a temporary job, suffer from a higher mental health distress, but when pay indicators are included statistically significance drops suggesting that there is a pay compensating element for the more stressful conditions demanded to workers with a permanent job (Robone et al. 2008). Also direct discrimination at the workplace increases the probability of mental distress.

In Table 3 we replicate our results using as dependent variable a ordered indicator for the intensity of mental health problems (i.e. cumulating up to 4 mental distress features) and, given the nature of the dependent variable, we fit an ordered probit model. To preserve space, we only report the estimated partial effects for the modal value of the morbidity distribution (i.e. the probability of cumulating at least two mental health problems), for the set of working conditions, as well as extra pay and job attributes. ${ }^{17}$ The partial effect of each single working conditions is smaller when we focus specifically on the probability of employees cumulating two (or more) mental health problems, suggesting that the effect of working conditions is mainly driven by the divide between those employees reporting mental health distress and the others,

\footnotetext{
${ }^{16}$ With respect to the existing literature results are mixed (Llena-Nozal, Lindeboom and Portrait, 2004).

${ }^{17}$ The partial effects for all levels of the mental health indicator are available upon request from the authors.
} 
Table 3: Mental health and working conditions, (ordered probit estimates, ME)

\begin{tabular}{|c|c|c|c|}
\hline & All & Female & Male \\
\hline OPROBIT & (1) & $(2)$ & $(3)$ \\
\hline discrimtot & $\begin{array}{c}.0434^{* * *} \\
(.0028)\end{array}$ & $\begin{array}{c}.0629^{* * *} \\
(.0042)\end{array}$ & $\begin{array}{c}.04345^{* * *} \\
(.00286)\end{array}$ \\
\hline bossw & $\begin{array}{l}.00208 \\
(.00197)\end{array}$ & $\begin{array}{l}.00053 \\
(.0037)\end{array}$ & $\begin{array}{l}.00208 \\
(.00197)\end{array}$ \\
\hline permanent & $\begin{array}{c}.00511^{* * * *} \\
(.00213)\end{array}$ & $\begin{array}{l}.0049 \\
(.0047)\end{array}$ & $\begin{array}{c}.00511^{* * * *} \\
(.00213)\end{array}$ \\
\hline repwo & $\begin{array}{c}.00694^{* * *} \\
(.00159)\end{array}$ & $\begin{array}{l}.0177^{* * *} \\
(.00353)\end{array}$ & $\begin{array}{c}.00694^{* * * *} \\
(.00159)\end{array}$ \\
\hline shift & $\begin{array}{c}.01621^{* * *} \\
(.00204\end{array}$ & $\begin{array}{c}.0303^{* * *} \\
(.0045)\end{array}$ & $\begin{array}{c}.01621^{* * *} \\
(.00204)\end{array}$ \\
\hline highwint & $\begin{array}{c}.02717^{* * *} \\
(.00166))\end{array}$ & $\begin{array}{c}.0399^{* * *} \\
(.0032)\end{array}$ & $\begin{array}{c}.02717^{* * *} \\
(.00166)\end{array}$ \\
\hline noasscolleg & $\begin{array}{c}-.00246^{* * *} \\
(.00212)\end{array}$ & $\begin{array}{l}.00^{* * *} \\
.00087)\end{array}$ & $\begin{array}{c}-.00246^{* * *} \\
(.00212)\end{array}$ \\
\hline lowJaut & $\begin{array}{c}.00681^{* * *} \\
(.00161)\end{array}$ & $\begin{array}{c}.00280^{* * *} \\
(.00067)\end{array}$ & $\begin{array}{c}.00681^{* * *} \\
(.00161)\end{array}$ \\
\hline compltask & $\begin{array}{c}.01685^{* * *} \\
(.00171)\end{array}$ & $\begin{array}{c}.00702^{* * *} \\
(.00077)\end{array}$ & $\begin{array}{c}.01685^{* * *} \\
(.00171)\end{array}$ \\
\hline whours & $\begin{array}{c}.01940^{* * *} \\
(.00202)\end{array}$ & $\begin{array}{l}.00812^{* * *} \\
(.00091)\end{array}$ & $\begin{array}{c}.01940^{* * * *} \\
(.00202)\end{array}$ \\
\hline ExPay & $\begin{array}{l}.0028^{* *} \\
(.0012)\end{array}$ & $\left(\begin{array}{l}.0018 \\
.0024)\end{array}\right.$ & $\begin{array}{l}.0016^{*} \\
(.0009)\end{array}$ \\
\hline pseudo- $\mathrm{R}^{2}$ & .068 & .086 & .066 \\
\hline Nobs & 34,652 & 16,843 & 17,809 \\
\hline \multicolumn{4}{|c|}{$\begin{array}{l}\text { Note:Significance levels: }{ }^{* * *} 1 \%, * * 5 \%,{ }^{*} 10 \% \text {; robust } \\
\text { standard errors in parentheses.Reference groups, ad- } \\
\text { ditional controls and variables coding as in Table } 2 . \\
\text { Marginal effects are reported for mentalh }=2\end{array}$} \\
\hline
\end{tabular}

rather than the intensity itself. One interesting question, in this respect, is whether some specific working conditions are more likely to be associated to specific mental health problems (Netterstrom, et al., 2008). We therefore run our empirical model separately for each specific mental health problem. The results, reported in Table 4, confirm the overall relevance of working conditions in affecting the various dimensions of mental health, still some interesting differences emerge if compared with the general indicator. For example the partial effect for employees that perform high intensity tasks is highest on stress at work (13 percentage points), while much smaller on irritability (5 percentage points), and sleeping problems and anxiety (2.2 and 2.9 percentage points, respectively). Large differences can be detected also for workers performing complex tasks: the partial effects range from 6.2 percentage points with stress at work, to 1.9 percentage points when sleeping problems are concerned.

Finally, in Table 5 we report a number of robustness checks based on the probit 
Table 4: Mental health (single items) and working conditions, (probit estimates, ME)

\begin{tabular}{|c|c|c|c|c|}
\hline & Stress & Anxiet & Sleep & Irrit \\
\hline PROBIT & $(1)$ & $(2)$ & $(3)$ & $(4)$ \\
\hline discrimtot & $\begin{array}{c}.170^{* * *} \\
(.018)\end{array}$ & $\begin{array}{c}.104^{* * *} \\
(.013)\end{array}$ & $\begin{array}{c}.090^{* * *} \\
(.012)\end{array}$ & $\begin{array}{c}.117^{* * *} \\
(.014)\end{array}$ \\
\hline bossw & $\begin{array}{l}.006 \\
(.010)\end{array}$ & $\begin{array}{l}.005 \\
(.004)\end{array}$ & $\begin{array}{l}.006 \\
(.005)\end{array}$ & $\begin{array}{l}-.003 \\
(.006)\end{array}$ \\
\hline permanent & $\begin{array}{l}.019^{*} \\
(.010)\end{array}$ & $\begin{array}{l}.007^{*} \\
(.004)\end{array}$ & $\begin{array}{l}.011^{* *} \\
(.004)\end{array}$ & $\begin{array}{l}-.005 \\
(.007)\end{array}$ \\
\hline repwo & $\begin{array}{c}.030^{* * *} \\
(.008)\end{array}$ & $\begin{array}{l}.007^{* *} \\
(.003)\end{array}$ & $\begin{array}{l}.002 \\
(.004)\end{array}$ & $\begin{array}{c}.017^{* * * *}(.005)\end{array}$ \\
\hline shift & $\begin{array}{c}.049^{* * *} \\
(.011)\end{array}$ & $\begin{array}{c}.019^{* * *} \\
(.005)\end{array}$ & $\begin{array}{c}.051^{* * *} \\
(.006)\end{array}$ & $\begin{array}{c}.038^{* * *} \\
(.007)\end{array}$ \\
\hline highwint & $\begin{array}{c}.131^{* * *} \\
(.008)\end{array}$ & $\begin{array}{c}.029^{* * *} \\
(.003)\end{array}$ & $\begin{array}{c}.022^{* * *} \\
(.004)\end{array}$ & $\begin{array}{c}.049^{* * * *}(.005) \\
\end{array}$ \\
\hline noasscolleg & $\begin{array}{l}-.016 \\
(.010)\end{array}$ & $\begin{array}{l}.002 \\
(.004)\end{array}$ & $\begin{array}{l}.007 \\
(.005)\end{array}$ & $\begin{array}{l}.006 \\
(.006)\end{array}$ \\
\hline lowJaut & $\begin{array}{c}.024^{* * * *} \\
(.008)\end{array}$ & $\begin{array}{l}.007^{* *} \\
(.003)\end{array}$ & $\begin{array}{l}.008^{* *} \\
(.004)\end{array}$ & $\begin{array}{c}.025^{* * * *} \\
(.005)\end{array}$ \\
\hline compltask & $\begin{array}{c}.062^{* * *} \\
(.008)\end{array}$ & $\begin{array}{c}.022^{* * *} \\
(.003)\end{array}$ & $\begin{array}{c}.019^{* * *} \\
.004)\end{array}$ & $\begin{array}{c}.029^{* * * *} \\
(.005)\end{array}$ \\
\hline whours & $\begin{array}{c}.090^{* * *} \\
(.011)\end{array}$ & $\begin{array}{l}.003 \\
.004)\end{array}$ & $\begin{array}{c}.023^{* * *} \\
(.006)\end{array}$ & $\begin{array}{c}.037^{* * * *} \\
(.007)\end{array}$ \\
\hline ExPay & $\begin{array}{l}.008 \\
(.005)\end{array}$ & $\begin{array}{l}-.001 \\
(.002)\end{array}$ & $\begin{array}{l}.002 \\
.002)\end{array}$ & $\begin{array}{l}.005^{*} \\
(.003)\end{array}$ \\
\hline pseudo- $\mathrm{R}^{2}$ & .097 & .1626 & .095 & .087 \\
\hline Nobs & 34,652 & 34,652 & 34,652 & 34,652 \\
\hline
\end{tabular}

specification $^{18}$. We run our preferred specification (column 2 in Table 2) separately for public (column 1) and private sector (column 2), for blue (column 3 ) and white collars (column 4) and by firm size (column 5 and 6). The results on the set of working condition variables are maintained within all subsamples (i.e. only the variable describing the disutility from low autonomy loses significance in some cases). The variable capturing discrimination at the workplace shows, as previously found, a positive relationship with mental distress, while extra pay components play a (statistically significant) role only for blue collars and small firms. Also separate regression by country were estimated testing the joint significance of the working condition dummies. Working conditions were always found to be statistically significant ${ }^{19}$.

As an additional check, we test whether working conditions are robust to the

\footnotetext{
${ }^{18}$ We also replicated results for the ordered probit model, results are not reported here to preserve space.

${ }^{19}$ The $\chi^{2}(7)$ test rejected for each single country the null hypothesis of working conditions being jointly not statistically significant.Results for single countries are available in the Appendix Table A2.
} 
inclusion of other perceived aspects of the job that may influence the likelihood that employees report mental health problems. We augmented our preferred specification with two different measures of reported job satisfaction (i.e. a dummy that takes value 1 if not satisfied, and a 4 levels indicator of job satisfaction). Results show that working conditions are unaffected by the inclusion of either measure of job satisfaction.

\section{$5.1 \quad$ Heterogeneity}

In the ordered response models estimated so far, the thresholds are treated as nuisance parameters which are necessary for the computations and are assumed to be the same for every individual in the sample. However, when comparing responses from different populations (i.e. demographic groups or countries), the distribution of the responses in the ordered scale may be influenced by linguistic or cultural differences (Daykin and Moffatt, 2002). The problem is known in the literature as "scale of reference bias"(Groot, 2001), or "state-dependent" reporting behaviour (Kerkhofs and Lindeboom, 1995; Lindeboom and van Doorslaer, 2004)) and occurs, as previously discussed, when different groups use systematically different threshold levels when assessing their health, despite having the same level of 'true' health. Alternatively, individuals may report mental health problems regardless of their true level of mental health. In this case, the thresholds are affected by the response behaviour, leading to a change of the relative position of the reporting thresholds. To account for this we use a generalisation of the ordered probit model (Terza, 1985; Williams, 2006) which allows the individual-specific thresholds $\left(c_{i}\right)$ to vary with different values of the covariates $(X)$, such as: $c_{i}=G_{i}\left(X ; \beta_{i}\right), i=1, \ldots, k-1$, where $k$ is the number of the response categories and the function $G_{i}(\cdot)$ can be used to investigate test the nature of reporting behaviour. In our specification, we estimate individual-specific thresholds with respect to demographic characteristics (gender and three age dummies) and, in alternative, with respect to an index of job satisfaction ${ }^{20}$. Our results show that the estimated coefficients of the generalised model - as compared to previous estimates - are very stable. When we test for thresholds heterogeneity, we find mix results. Demographic characteristics do not appear to influence response thresholds, as we cannot reject the restricted model with fix thresholds; conversely, we find evidence

\footnotetext{
${ }^{20}$ In practice, to estimate the thresholds, we used a linear function of the demographic terms and, alternatively, the job satisfaction index. The error term is assumed to have a standard normal distribution.
} 
that the index of job satisfaction affects response behaviour shifting the estimated thresholds ${ }^{21}$. In other words, workers who appear to be less satisfied with their job also seem to be more likely to report mental health problems. Note, however, that while in this case we can reasonably reject the hypothesis of homogeneity of thresholds, we cannot distinguish whether the effect of job satisfaction reflects reporting behaviour or a "true" health effect (Lindeboom and van Doorslaer, 2004)22

\subsection{Endogeneity}

The estimates presented in the previous section are based on the maintained hypothesis that working conditions are exogenous to workers's mental health status. There are, however, many reasons to believe that mental health distress and the allocation of workers to jobs with differing working conditions might not be independent, or that mental health itself could influence firms choice vis à vis job attributes. In all these cases, the endogentiy of working condition may bias our results. For example, as already mentioned, (endogenous) sorting may govern the allocation of workers across jobs and firms with different working conditions, such that more risk-adverse workers may look for jobs with more stringent safety regulations and better work organization practices which minimise risks and hazard at work. Firms may also choose safety attributes and related expenditures according to workers' mental attitudes or hidden actions in exerting precaution effort. ${ }^{23}$ In this section, to address the (potential) endogeneity of workplace attributes and identify the (causal) effect of working conditions on mental health, we implement an instrumental variables full information maximum likelihood probit. ${ }^{24}$ In practice, we first introduce a summary index of working conditions (WCtot), as previously described, and then select two variables which we use as instruments in the estimations. The first instrument is a regulation index of occupational health and safety, which proxies the level of government inter-

\footnotetext{
${ }^{21}$ The likelihood ratio test for homogeneity in response behaviour always rejects the null at the 1 percent level of significance.

${ }^{22}$ As discussed in, this is a fundamental identification problem that cannot be addressed in this context, without resorting to external information (i.e. objective "true" halth measures or anchoring vignettes).

${ }^{23}$ Not to neglect that working conditions may also be subject to measurement error.

${ }^{24}$ Maximum likelihood estimator is computationally feasible in a large sample, as in our analysis, and it guarantees desirable properties. Indeed, it is asymptotically normally distributed and asymptotically efficient; in addition, approximate significance tests of parameters are statistically valid and the tests are easy to compute.
} 
vention in promoting health and safety at work. ${ }^{25}$ More specifically it measures the number of ratifications of ILO conventions, with respect to general aspects of the job, implemented between 1995 and 2005 in the countries included in our sample. Hence, government's regulations is expected to influence firms decisions - in terms of work environment and job attributes - inducing them to exert the socially optimal level of health and safety precaution henceforth altering working conditions. The identifying assumption here is that more stringent regulations improve overall working conditions at the workplace, while not being correlated with the unobservables of the mental health equation. The second variable is based on an index of high performance work organisation (HPWO) defined by industry and occupation. We use firms' practices aimed at improving work organisation such as, increasing employee involvement (i.e. "Have you undergone training paid by employees/on the job training?", "Does your job involve teamwork?") and responsibility for quality control ("Does your main job involve meeting precise quality standards?"), to proxy for the pressure coming from international competition and from technological shocks on overall working conditions at the workplace. A wide literature on HPWO practices (Gittleman et al., 1998, and Osterman, 2000) has shown that improvements in work processes and the quality of products are directly related to the diffusion of innovations in organisational practices and working conditions arrangements. In practice, we create a summary measure of work organization summing up all the dummy variables related to high-performance work organisation practices (hiperfpract), such as: meeting precise quality standards, learning new things at work, discretion in fixing order of tasks, choosing methods of work and in setting speed of work, undergone training paid by employee or on the job training.

In order to facilitate comparisons with previous estimates, in Table 6 column (1), we report estimates from a simple probit using the summary measure of working conditions and, in column (2), we show the IV estimates for the same variable. Columns 3 to 6 , in the same table, also report results by gender. IV estimates show a positive and statistically significant effect of overall working conditions on the probability of experiencing mental health problems. Note, that the larger estimated coefficient seem to suggest that measurement error and selection are likely to affect the simple probit estimates and underestimate the true effect. The causal effect of reporting at least

\footnotetext{
${ }^{25}$ The ILO_index, has been constructed using ILO Directives Archive http://www.ilo.org/ilolex/). A complete description of this index can be found in the appendix.
} 
Table 5: Mental health and working conditions, by subgroups (Probit estimates, ME)

\begin{tabular}{lcccccc}
\hline & public & private & blue collar & white collar & small firm & big firm \\
\hline & $(1)$ & $(2)$ & $(3)$ & $(4)$ & $(5)$ & $(6)$ \\
\hline discrimtot & $0.233^{* * *}$ & $0.137^{* * *}$ & $0.141^{* * *}$ & $0.236^{* * *}$ & $0.234^{* * *}$ & $0.160^{* * *}$ \\
bossw & 0.013 & -0.001 & 0.009 & 0.004 & 0.007 & 0.004 \\
permanent & $0.036^{*}$ & 0.003 & 0.009 & 0.009 & 0.006 & 0.016 \\
repwo & $0.034^{* * *}$ & $0.031^{* * *}$ & $0.026^{* *}$ & $0.049^{* * *}$ & $0.044^{* * *}$ & $0.027^{* * *}$ \\
shift & $0.101^{* * *}$ & $0.058^{* * *}$ & $0.075^{* * *}$ & $0.086^{* * *}$ & 0.100 & $0.022^{* * *}$ \\
highwint & $0.080^{* * *}$ & $0.126^{* * *}$ & $0.125^{* * *}$ & $0.125^{* * *}$ & $0.117^{* * *}$ & $0.144^{* * *}$ \\
noasscolleg & -0.013 & -0.021 & $-0.024^{*}$ & -0.023 & -0.035 & $-0.0003^{* *}$ \\
lowJaut & 0.016 & $0.022^{*}$ & 0.019 & $0.029^{* * *}$ & 0.041 & $-0.011^{* * *}$ \\
compltask & $0.118^{* * *}$ & $0.041^{* * *}$ & $0.055^{* * *}$ & $0.071^{* * *}$ & $0.061^{* * *}$ & $0.076^{* * *}$ \\
whours & $0.085^{* * *}$ & $0.086^{* * *}$ & $0.099^{* * *}$ & $0.093^{* * *}$ & $0.094^{* * *}$ & $0.099^{* * *}$ \\
ExPay & 0.014 & 0.009 & 0.024 & 0.003 & 0.004 & $0.025^{* * *}$ \\
\hline pseudo-R $\mathrm{R}^{2}$ & .137 & .098 & .099 & .115 & .108 & .114 \\
Nobs & 40,306 & 34,652 & 40,306 & 34,652 & 16,843 & 17,809 \\
\hline \hline
\end{tabular}

Note:Significance levels: $* * * 1 \%, * * 5 \%,{ }^{*} 10 \%$.Reference groups, additional controls and variables coding as in Table 2. Marginal effects are reported.

one mental health problem is increased by 26 percentage points by overall (adverse) working conditions at the workplace (as compared to the 6.4 percentage points of the simple probit). ${ }^{26}$ Results are robust when we split the sample by gender. Some interesting differences appear. Having a woman as a boss, as shown in psychological studies (Eagly and Johannesen-Schmidt, 2001), seems to reduce the likelihood of mental health distress among women while it is still not (statistically) significant for men. The effect of (adverse) working conditions on mental health is higher for men as compared to women (28.8 and 26.3 percent, respectively). As a final check, we tested the exogeneity assumption and the validity of our instruments. The Wald chi-squared test of exogeneity reported at the bottom of the table, rejects the null that working conditions are exogenous.

\section{Discussion}

While we have documented that, in several European countries, (adverse) working conditions affect mental health, some differences emerge across countries in the determinants of mental health. As previously discussed, few features emerge in all countries

\footnotetext{
${ }^{26}$ Of course the policy implications of these estimates must be evaluated with caution. For instance, since the impact of (adverse) working conditions estimated by the IV methodology includes also all unmeasured characteristics that are correlated with both working condition and the instrumental variables, the effect of policy changes that alter health and safety at the workplace (without changing these unobserved factors) may be overstated.
} 
Table 6: The effect of working conditions on mental health, (Probit and IV-Probit estimates, ME)

\begin{tabular}{|c|c|c|c|c|c|c|}
\hline & \multicolumn{2}{|c|}{ All } & \multicolumn{2}{|c|}{ Female } & \multicolumn{2}{|c|}{ Male } \\
\hline & (Probit) & (IV-Probit) & (Probit) & (IV-Probit) & (Probit) & (IV-Probit) \\
\hline & (1) & $(2)$ & $(3)$ & $(4)$ & $(5)$ & $(6)$ \\
\hline female & .007 & $.029^{* * *}$ & & 2 & & \\
\hline agecl2 & $.073^{* * *}$ & $.053^{* * *}$ & $.101^{* * *}$ & $.081^{* * *}$ & $.049^{* * *}$ & ,032 \\
\hline agecl3 & $.101^{* * *}$ & $.069^{* * *}$ & $.111^{* * *}$ & $.098^{* * *}$ & $.089^{* * *}$ & .043 \\
\hline agecl4 & $.076^{* * *}$ & $.075^{* * *}$ & $.114^{* * *}$ & $.116^{* * *}$ & $.045^{* * *}$ & $.042^{* * *}$ \\
\hline educmid & -.026 & .004 & $-.038 * *$ & -.019 & .001 & -.016 \\
\hline educhigh & $-.015^{* * *}$ & .023 & .004 & .0201 & -.010 & .024 \\
\hline child & .001 & -.012 & .0017 & -.0098 & .0015 & -.0119 \\
\hline spousepart & $-.021^{* *}$ & -.006 & $-.024^{* *}$ & -.001 & -.125 & -.0089 \\
\hline discrimtot & $.198^{* * *}$ & .008 & $.225^{* * *}$ & -.0485 & $.169^{* * *}$ & -.0187 \\
\hline bossw & .003 & $-.017^{*}$ & .0099 & $-.0251 * *$ & .017 & .0157 \\
\hline permanent & .018 & -.018 & .005 & $-.0277^{*}$ & $.031^{* * *}$ & -.0089 \\
\hline ExPay & $.019^{* * *}$ & $-.021^{* *}$ & $.019^{* * *}$ & $-.021 *$ & $.019^{* * *}$ & -.022 \\
\hline WCtot & $.060^{* * *}$ & $.276^{* * *}$ & $.058^{* * *}$ & $.263^{* * *}$ & $.0625^{* * *}$ & $.288^{* * *}$ \\
\hline Nobs & 35,247 & 35,247 & 17,296 & 17,296 & 17,951 & 17,951 \\
\hline
\end{tabular}

as particularly harmful for mental health at the workplace, they are: working at very high speed and tight deadlines, having low job autonomy and being involved in complex tasks. Other features, such as: number of hours worked, working in shifts or doing repetitive work, show a higher variation both in size, as well as statistical significance across countries. It is of course the case that countries that are characterised by a high score in the index of mental health distress (such as, Greece, Sweden and Italy), also report the worst combination for all the above features, while those with a lower score (such as, The Netherland, United Kingdom and Ireland) present milder effects and fewer attributes that are statistically significant. ${ }^{27}$

Given that European countries operate under similar market conditions, share comparable technological attributes, have universal health coverage and a widespread social safety net, the existence of substantial differences, both in the incidence and

\footnotetext{
${ }^{27}$ Other results worth mentioning, outside the standard working conditions controls, are the strong effect, in all countries, of the discrimination dummy. Being discriminated at work is by far the worst determinant of mental health. Also, while in most countries women are worse off in terms of mental health at the workplace, in some countries (such as Ireland, United Kingdom, Sweden, Germany and Denmark) there is no statistical difference across gender, while in The Netherlands the sign on the female dummy is reversed (also statistically significant).
} 
gravity of psychological and mental distress at the workplace, is a puzzling phenomenon. In this section, we discuss the sources of such differences, accounting for the role played by two sets of institutions which may affect both working conditions and health, namely: health and safety regulations at the workplace, and labour market regulations. In other words, we would like to find out whether any combination of these two types of regulations can explain some of the cross-country mental health patterns we observe. Note that, while an extensive literature has documented the effects of labour market institutions on various economic outcomes (such as unemployment, wages, productivity growth) ${ }^{28}$, there are no studies that have investigated, in a cross-country perspective, the effects on work related health outcomes. To this end, we merged some post-estimation data (country fixed-effects), with information drawn from different sources: labour market regulation (Labour Market Institution Database, LMID) and health and safety regulation at the workplace (ILO Directives Archives, ILODA). In practice, we combined the mental health "country fixed-effects" (i.e. "net" of individual and workplace characteristics), ${ }^{29}$ with (time-varying) indicators of health and safety regulations (i.e. number of ratifications of ILO's directives regarding safety at work), labour market regulations (i.e. employment protection legislation for regular and temporary contract, union density) and the unemployment rate to account for business cycle effects. The final data set, that we use in the empirical analysis below, is a cross-section/time-series (15 countries, for the years 1995, 2000, and 2005) with 90 observations. ${ }^{30}$ We perform a principal component analysis and extract the first two components, which we interpret along the "labour market regulation" (LMR, $1^{\text {st }}$ component) and "health and safety regulation" (HSR, $2^{\text {nd }}$ component) dimensions. ${ }^{31}$ In Figure 3, we plot the score associated to each component by country, such that the scattered points can be interpreted as a synthetic measure

\footnotetext{
${ }^{28}$ See Bassanini and Duval (2009) for a recent survey of the evidence.

${ }^{29}$ These are derived from a first stage mental health estimation, by gender and year, with controls for demographics, job and industry attributes. More specifically, we use the country fixed effects from the regressions in Table 3 (columns 5 and 6 ) estimated separately for each year.

${ }^{30}$ Note that, in order to increase the degree of fredoom of our analysis, the country FE were estimated separately for males and females: hence, the total number of observations is given by $15 x 3 \times 2=90$. In the empirical analysis we also include a control for gender.

${ }^{31}$ The first two components account for over 70percent of the total variance in the data. The first component bears a positive correlation with the mental health FE, all labour market institutions and the unemployment rate, while the second component shows a negative correlation with the mental health FE and a positive correlation with the ILO-index.
} 


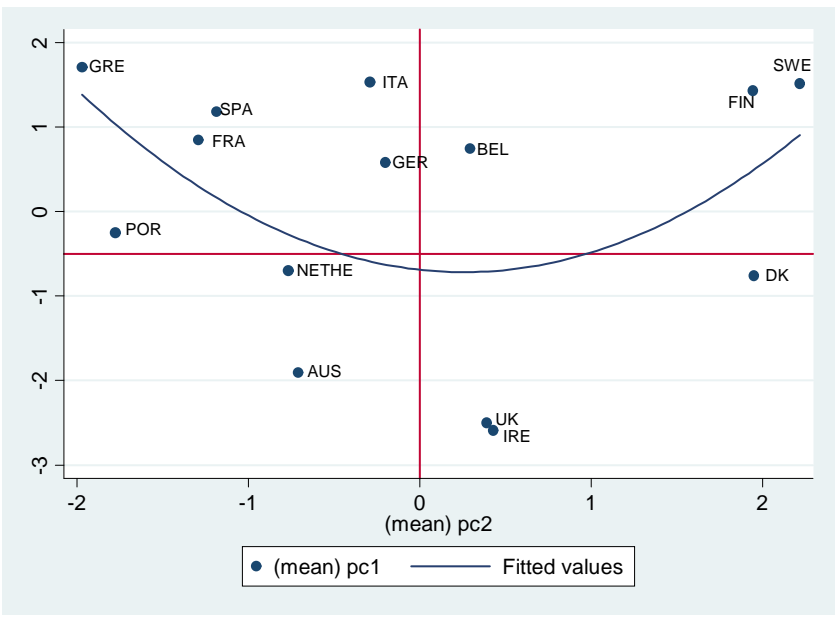

Figure 3: Country patterns in LMR and HRS, (Principal component analysis)

of the institutional environment affecting mental health at the workplace.

The distribution of countries suggest that a high $L M R$ is associated to critical levels of mental health distress, as the countries located in the upper quadrants are also the ones which report the highest incidence of mental health distress at work (i.e. Greece, Sweden, Italy, Finland, see Fig.1). Moving along the $S H R$ axis, we find that countries with higher level of health and safety regulation at work are also the one that report, on average, lower levels of mental health distress (i.e. Ireland, United Kingdom and Denmark, see Fig.1). However, this seems to be true only if combined with low levels of $L M R$, since Sweden and Finland that have both high $S H R$ and $L M R$ also have a high incidence of mental health problems (see Fig.1). In practice, as shown in Figure 3, there seems to be evidence of a $U$ shaped relationship linking $L M R$ and $S H R$ to mental health distress. One explanation for the above patterns may come from the interactions of the different types of institutions in imperfect labour markets. In this context, while higher health and safety standards have beneficial effects on mental health at work, the presence of stringent labour market regulations may affect workers both on the "intensive" and "extensive" margins. On the one hand, incumbent workers (the insiders), may have to face more stressful working conditions (intensive margin) to mach firms' performance requirements; on the other hand, more marginal workers (the outsiders) may bear most of the adjustment costs in terms of bad working conditions, job mismatch and precarious contractual provisions over the business cycle (extensive margin). Hence, while the extensive margin 
may prevail in countries with high $L M R$ and low $S H R$ (upper left quadrant), the intensive margin should dominate in countries with both high $S H R$ and $L M R$ (upper right quadrant). Finally, countries located in intermediate positions, as to the institutional environment, seem to experience a more favourable trade-off in terms of mental health distress at work. Quite interestingly, the cluster of countries that emerges from Figure 3 is reminiscent of the widely used classification of countries in "Scandinavian", "Mediterranean", "Continental European" and "Anglosaxon" which have been shown to share common characteristics along several socioeconomic dimensions (Esping-Andersen, 1990), but not yet in terms of implications for mental health regimes.

\section{Concluding Remarks}

This study provides evidence on the much debated increase in mental health distress among European workers. We use three waves (1995, 2000 and 2005) of the European Working Conditions Survey to document recent patterns in mental health at the workplace and to assess how employment arrangements and working conditions influence psychological and mental health status in 15 European countries. Our main results suggest that there is substantial heterogeneity in mental health conditions at the workplace both across workers, as well as between countries. We show that a set of workplace attributes, such as: working in shifts, performing complex and intensive tasks and having restricted job autonomy lead to a higher probability of reporting mental health problems. We test the robustness of our estimates in various ways and implement a methodology for differential reporting in ordered response models which allows for threshold shifts. We show that workers that are particularly unhappy about their job conditions are, ceteris paribus, more likely to report mental health problems, while we detect no differences by gender or age. We also account for the potential endogeneity of working conditions, given by workers sorting across heterogeneous jobs and firms health and safety expenditures, and provide evidence of a positive causal effect of adverse working conditions on mental health distress. We show that neglecting endogeneity is likely to bias estimates towards zero.

Finally, we discuss the differences in conditional means (i.e. "net" of individual and workplace characteristics) of mental distress at the workplace across countries, accounting for the role played by the institutional setting. In particular, we show that 
health and safety regulations $(S H R)$ at the workplace and labour market institutions $(L M R)$ can explain a significant part of the cross-country differences. We find a $\mathrm{U}$ shaped relationship linking $L M R$ and $S H R$ to mental health distress. That is, countries with high levels of $L M R$ and low levels of $S H R$ are associated to critical levels of mental health distress (Greece, France and Italy), while higher levels of $S H R$ and intermediate level of $L M R$ appear, on average, to reduce workers' mental health distress (Austria, Ireland, United Kingdom and Denmark). Conversely, countries with both high $S H R$ and $L M R$ show a high incidence of mental health problems (Sweden and Finland). We interpret this evidence in terms of the role that institutions play in imperfect labour market, where different combination of $L M R$ and $S H R$ may affect workers' mental health status either through the "intensive margin", more demanding working conditions to mach firms' performance requirements, or the "extensive margin", where workers face higher adjustment costs in terms of bad working conditions, job mismatch and precarious contractual provisions.

Overall our results support the perception, which is currently debated in Europe, that adverse contractual and working conditions can have a negative influence on the psychological well-being and mental health status of workers. The policy implications of the above findings invest several domains of the public interest. First, improving the mental health and psychological well-being of workers by increasing the quality of jobs is correctly perceived as a priority: not just with concern to well-being and general health considerations, but also in terms of cost-effectiveness since mental health problems have become a major source of public spending in most European countries. Second, in terms of efficiency, workers in good mental health are likely to be more productive and more satisfied with their job. The macroeconomic implications, at the European level, of policies targeted to the further improvement of working conditions could be substantial and, as such, should feature high in the agenda of policy makers. 


\section{References}

Angrist, J. D. and Krueger, A. B. (1992). "The effect of age at school entry on educational attainment: an application of instrumental variables with moments from two samples.", Journal of the American Statistical Association, 87(418), $328-336$.

Arellano, M. and Meghir, C. (1992), "Female labour supply and on-the-job search: an empirical model estimated using complementary data sets.", Review of Economic Studies, 59(3), 537-559.

Aronsson G. and Goransson, S. (1999),"Permanent employment not in a preferred occupation: psychological and medical aspects, research implications", Journal of Occupational Health Psychology, 4, 152-63

Artazcoz, L., Benach, J.,Borrell, C and Cortes, I. (2005), "Social inequalities in the impact of flexible employment on different domains of psychological health", Journal of Epidemiology and Community Health, 59(9), 761-767.

Bardasi E. and Francesconi M. (2004), "The impact of atypical employment on individual well-being: evidence form a panel of British workers", Social Science and Medicine, 58,1671-1688

Bassanini A., R. Duval (2009), "Unemployment, institutions and reform complementarities: Re-assessing the aggregate evidence for OECD countries", Oxford Review of Economic Policy, 25(1), 40-59.

Blanchflower, D.G. and Oswald, A.J. (2008),"Hypertension and happiness across nations", Journal of Health Economics, 27(2), 218-233

Bockermann P. and P. Ilmakunnas, (2007), "Job Disamenities, Job Satisfaction, Quit Intentions, and Actual Separations: Putting the Pieces Together", Industrial Relations, 48 (1), 73-96.

Bratti M, Del Bono E, Vuri D.(2005),"New Mothers' Labour Force Participation in Italy: The Role of Job Characteristics", Labour, 19; 79-121.

Burströmm, B., Fredlund, P., (2001), "Self rated health: Is it as good a predictor of subsequent mortality among adults in lower as well as in higher social classes?", Journal of Epidemiology and Community Health 55, 836-840.

Cappelli P., Bassi L., Katz H., Knoke D., Osterman P.and Useem M., (1997), "Change at work", Oxford University Press,New York.

Clark, A. (2003), "Unemployment as a Social Norm: Psychological Evidence from Panel Data", Journal of Labour Economics; 21(2), 323-350. 
Datta Gupta, N., Kristensen, N., (2007), "Work environment satisfaction and employee health: panel evidence from Denmark, France and Spain, 1994-2001", European Journal of Health Economics, 9(1), 51-61.

Daykin, A. and P. Moffatt , (2002), "Analyzing Ordered Responses: A Review of the Ordered Probit Model", Understanding Statistics, I, 3, 157-166.

Eagly, A. H., and Johannesen-Schmidt, M. (2001), "The leadership styles of women and men", Journal of Social Issues, 57, 781-797.

Ferrie, J., Shipley, M., Marmot, M. G., Stansfeld, S. and Davey Smith, G. (1999), "An uncertain future: the Health effects of organisational change and job insecurity health effects of threats to employment security in white-collar men and women", American Journal of Public Health., 88(7), 1030-1036

Garcia Gomez P. and Lopez Nicolas A. (2006), " Health shocks, employment and income in the Spanish labour Market", Health Economics, 15,997-1009.

Gittleman M., Horrigan M. and Joyce M. (1998), "Flexible" Workplace Practices: Evidence from a Nationally Representative Survey", Industrial and Labor Relations Review, 52(1), 99-115

Godin I. and Kittel F.(2004),"Differential economic stability and psychosocial stress at work: associations with psychosomatic complaints and absenteeism", Social Science and Medicine, 58,1543-1553

Goldberg, D.P., Gater, T., Sartorious, N., Ustun, T.B., Piccinelli, M., Gureje, O., Rutter, C., (1997)," The validity of two versions of the GHQ in the WHO study of mental illness in general health care", Psychological Medicine 27, 191-197.

Gravelle, H., Sutton. M., (2009), "Income, relative income, and self-reported health in Britain 1979-2000", Health Economics, 18, 125-145..

Groot, W. (2000), "Adaptation and scale reference bias in selfassessments of quality of life", Journal of Health Economics,19, 403-420.

Idler, E.L., Benyammi, Y., (1997),"Self-rated health and mortality: a review of twenty-seven community studies", Journal of Health and Social Behavior, 38, 21-37.

Joubert, N. and Stephens T. (2001), " The Economic Burden of Mental Health Problems in Canada", Chronic Disease in Canada, 22

Kasl, S. V. (1998),"Measuring job stressors and studying the health impact of the work environment: An epidemiological commentary", Journal of Occupational Health Psychology, 3, 1-12.

Kerkhofs, M., Lindeboom, M., (1995) "Subjective health measures and state dependent reporting errors", Health Economics, 4, 221-235.

Layard, R. (2005), "Lessons From a New Science", Publisher Penguin Press. 
Leigh, A., Jencks, S. and Smeeding T. (2009) "Health and Economic Inequality", in Salverda, W., Nolan, B. and Smeeding T. (eds) The Oxford Handbook of Economic Inequality, Oxford University Press, Oxford.

Lindeboom, M. and van Doorslaer, E. (2004),"Cut-point shift and index shift in self-reported health", Journal of Health Economics, 23, 1083-1099

Lundberg, U., and Frankenhaeuser, M. (1999), "Stress and workload of men and women in high-ranking positions", Journal of Occupational Health Psychology, 4, 142-151.

Llena-Nozal, A., M.Lindeboom and F. Portrait (2004), " The effect of work on mental heath: does occupation matter?", Health Economics, 13,1045-1062

Madden, D. (2008),"Gender Differences in Mental Well Being: A Decomposition Analysis", HEDG Working Paper 08/08

Marchand A., Demers A.and Durand P. (2005), "Do occupation and work conditions really matter? A longitudinal analysis of psychological distress experiences among Canadian workers", Sociology of Health and Illness, 27,602-627.

Marusic, A. (2004), "Mental Health in the enlarged European Union: need for relevant public mental Health action", British Journal of Public Phsychiatry, 184, $450-451$

Oecd (2008), "Are all Jobs Good for your Health? The Impact of Work Status and Working Conditions on Mental health", Chapter 4 (Author Ana llena-Lozal) OECD Employment Outlook, OECD Paris

Netterstrom, B, Conrad, N., Bech, P., Fink, P., Olsen, O., Rugulies, R., and Stansfeld, S. (2008), "The relationship between work-related psychosocial factors and the development of depression", Epidemiologic Reviews, 30, 118-132.

Osterman, P. (2000), " Work reorganization in an era of restructuring: trends in diffusion and effects of employee welfare", Industrial and Labor Relations Review, $53,179-96$

Oswald, A.J. and Wu, S. (2009),"Well-being across America", IZA DP N. 4600

Parent-Thirion, A., E.F. Macias, J. Hurley and G. Vermeulen (2007),"Fourth European Working Conditions Survey", European Foundation for the Improvement of Living and Working Conditions, Luxembourg

Paoli, P. and Merllié, D. (2001),"Third European Survey on Working Conditions 2000", European Foundation for the Improvement of Living and Working Conditions, Luxembourg:Office for Official Publication of the European Communities.

Pikhart, H., Bobak, M., Pajakb, A., Malyutin, S., Kubinov, R., Topor, R., Sebakova, H., Nikitin, Y., and Marmot, M. (2004), "Psychosocial factors at work and 
depression in three countries of Central and Eastern Europe", Social Science and Medicine, 58, 1475-1482.

Rice, N., Robone, S. and Smith, P.C. (2009), "Vignettes and health systems responsiveness in cross-country comparative analyses", HEDG Working Paper 09/29.

Robone S., Jones A.M. and Rice N. (2008), " Contractual conditions,working conditions, health and well being in the British Household Panel Survey", HEDG working paper 08/19

Rosen, S. (1986), "The theory of equalizing differences", in Ashenfelter, O. and Layard, R. (Eds), Handbook of Labor Economics,Vol. 1, Elsevier, Amsterdam, pp. 642-92.

Rugulies R., Bultmann U., Aust B., Burr H.(2006), "Psychosocial work environment and incidence of severe depressive symptoms: prospective findings from a 5-Year follow-up of the Danish Work Environment Cohort Study", American Journal of Epidemiology, 163: 877-887.

Schieman, S., Whitestone, Y.K. and Van Gundy, K. (2006), "The nature of work and the stress of higher status", Journal of Health and Social Behavior, 47, 242-257.

Terza, J., (1985), "Ordered Probit: A Generalization," Communications in Statistics - A. Theory and Methods, 14, 1-11

Theodossiou I., "The effects of low pay and unemployment on psychological wellbeing: a logistic regression approach", Journal of Health Economics,17:85-104.

The Mental Health Foundation, (2000), "The cost of mental health problems. The Fundamental fact", www.mentalhealth.org.uk/publications/fundamental - facts/

Vermeulen, M., and Mustard, C. (2000), "Gender differences in job strain, social support at work, and psychological distress", Journal of Occupational Health Psychology, 5, 428-40.

Warren, L.R., Hoonakker, P., Carayon, P., Brand, J., (2004), "Job characteristics as mediators in SES-health relationship", Social Science $\&$ Medicine, 59, 13671378 .

Williams, R., (2006), "Generalized Ordered Proportional Odds Models for Ordinal Dependent Variables", The Stata Journal, 6, 1, 58-82. 


\section{A Appendix}

\section{A.1 Data Sources}

\section{A.1.1 European Working Conditions Survey}

In this study we use three waves (1995, 2000 and 2005) of the European Working Conditions Survey (EWCS), which is based on a standardised questionnaire administered face-to-face to a representative sample of the employed population in each country of the European Union ${ }^{32}$. The survey has been developed by the European Working Conditions Observatory. The data cover employed individuals of 15 years of age and over ${ }^{33}$. In the 2005 wave, 31 countries were included in the survey: EU27 plus Croatia, Turkey, Switzerland and Norway. Since we are also using earlier waves, for comparability purposes our sample is restricted to EU15 countries (i.e. Greece, Sweden, Italy, Finland, Luxemburg, France, Portugal, Belgium, Spain, Denmark, United Kingdom, Germany, Netherlands, Austria and Ireland).The coverage of the EWCS reflects the evolution of the European Union, as more states have joined over time. In 1995, the survey covered the $15 \mathrm{EU}$ member states of the time (EU15). In 2000 the EU15 countries plus Norway were covered. In 2005 the survey included 31 countries including the 27 current EU member states (EU27) plus Croatia, Turkey, Switzerland and Norway in 2005 (though it should be noted that two of the EU27, Romania and Bulgaria, did not fully accede to the EU until 2007). EWCS data provide detailed information on both work-related psychological problems, as well as job attributes. While, the number of questions and issues covered in the EWCS has expanded over time, still a core of questions have remained unchanged across the different waves, allowing a comparative study of the changes in working conditions and their effects. The EWCS1995, EWCS2000 and EWCS2005 were carried out following standard procedures by INRA (Europe), the European Coordination Office, that assessed the quality of data collection and the database preparation, in close cooperation with the Occupational National Institutes and Eurostat. Details of sampling methods are provided elsewhere (Paoli and Merllié, 2001).

\footnotetext{
${ }^{32} \mathrm{~A}$ person is considered as being in employment if he or she did any work for pay or profit during the reference week for at least one hour.

${ }^{33}$ Some countries apply a different lower age limit (16 in Spain,United Kingdom and Norway) and some other use an upper age limit (74 in Denmark, Ireland, Finland, Sweden and Norway).
} 


\section{A.1.2 ILO Directives Archive}

Safety and health in the labour market is regulated also through international legislation in particular the most important guidelines about occupational health and safety services are provided by the International Labour Organisation. ILO Member States have to ratify these regulations before implementing them into the national legislation however countries can freely decide if and when to ratify ILO Conventions and Recommendations. In this paper we construct an index of ILO ratifications (ILO_index) implemented in each country in the period 1995-2005, these informations are derived from. www.ilo.org/ilolex/english. The ratifications considered consist in two groups. The first provides general guidelines about occupational health and safety services (and includes C 155: Occupational safety and health Convention (1981); C 161: Occupational health services Convention (1985); C 174: Prevention of major industrial accident Convention (1993); C 187: Promotional framework for occupational safety and health Convention (2006); P 155: Protocol of 2002 to the occupational safety and health Convention), while the second consists in those regulating the protection of workers against specific hazards experienced at the workplace (namely : C 13: White lead Convention (1921); C 115: Radiation protection Convention (1960); C 119: Guarding of machinery Convention (1983); C 120: Hygiene Convention (1964); C 127: Max weight Convention (1967); C 136: Benzene Convention (1971); C 139: Occupational cancer Convention (1974); C 148: Working environment (air pollution, noise and vibration) Convention (1977); C 162: Asbestos Convention (1986); C 170: Chemicals Convention (1990)). Obviously there are differences on the number of conventions ratified by each EU country included in the empirical analysis and the ILO_index was constructed in a progressive way, in order to capture the increase in the number of ratifications implemented by each country at the three points in time observed in the data.

\section{A.1.3 OECD Labour Market Institution Database (LMID)}

The OECD 'Labour Market Institution Database' (LMID) collects information on labour market institutions for OECD countries (see www.oecd.org/document). Among these we focus on the indicators listed below:

- Unemployment rate(urt1564): unemployed (employed) workers as share of the labour force (working-age population), in \%. Aggregate rates refer to the 15- 
64 age group.Source: OECD, Database on Labour Force Statistics; OECD, Annual Labour Force Statistics. Data adjustments: while the primary source is the OECD Database on Labour Force Statistics.

- Union density (undens):trade union density rate, i.e. the share of workers affiliated to a trade union, in \%; Source: OECD, Employment Outlook

- EPL: the OECD indicator of EPL comprises two main components, namely EPL on temporary contracts and EPL on permanent contracts.

\section{A.2 Additional Tables}

Table A1: Variables Definition

\begin{tabular}{|c|c|c|}
\hline Name & Definition & Mean \\
\hline mentalh & $\begin{array}{c}\text { takes values } 0 \text { to } 4 \text { and it is the sum of } 4 \text { mental health indicators } \\
\text { (stress,irritability,sleep,anxiety) }\end{array}$ & .048 \\
\hline mentalh-dum & 1 if at least one mental health problem has been mentioned, 0 otherwise & .302 \\
\hline stress & 1 if experiences stress due to his/her job, 0 otherwise & .238 \\
\hline irrit & 1 if feels irritability due to his/her job, 0 otherwise & .104 \\
\hline sleep & 1 if has problems to sleep due to his/her job, 0 otherwise & .072 \\
\hline anxiet & 1 if experiences anxiety due to his/her job, 0 otherwise & .073 \\
\hline agecl1 & 1 if in the age group 16 to 25 , and 0 otherwise & .134 \\
\hline agecl2 & 1 if in the age group 26 to 35 , and 0 otherwise & .205 \\
\hline agecl3 & 1 if in the age group 36 to 45 , and 0 otherwise & .284 \\
\hline agecl4 & 1 if in the age group 46 to 64 , and 0 otherwise & 317 \\
\hline educlow & 1 if the highest level of education is primary education, 0 otherwise & 338 \\
\hline educmid & 1 if highest level of education is secondary education, 0 otherwise & .169 \\
\hline educhigh & 1 if hiest level of education is tertiary education, 0 ottherwise & .254 \\
\hline female & 1 if female, 0 otherwise & .464 \\
\hline child & 1 if has at least one child and 0 otherwise & .422 \\
\hline spousepart & 1 if has a spouse or a partner, 0 otherwise & .649 \\
\hline permanent & 1 if if current job is a full time permanet job, 0 otherwise & .815 \\
\hline bossw & 1 if the boss is a woman, 0 otherwise & .219 \\
\hline public & 1 if works in the public sector, 0 otherwise & .267 \\
\hline repwo & 1 if main job involves repetitive arms or legs movements, 0 otherwise & .419 \\
\hline shift & 1 if works in shifts, 0 otherwise & .148 \\
\hline highwint & $\begin{array}{c}1 \text { if job involves working at very high speed or stick to tight } \\
\text { deadlines, } 0 \text { otherwise }\end{array}$ & .452 \\
\hline discrimtot & 1 if has been subject to some kind of discrimination at work, 0 otherwise & .064 \\
\hline noasscolleg & 1 receive no assitance from collegues at work, 0 otherwise & .315 \\
\hline lowJaut & 1 if not able to choose order of tasks, method or speed of work, 0 otherwise & .464 \\
\hline compltask & 1 if main job involves complex tasks, 0 otherwise & .570 \\
\hline whours & 1 if working hours are more than 40 hours a week, 0 otherwise & .241 \\
\hline ExPay & Sum of indicators of extra payments & .526 \\
\hline WCtot & Sum of working condition indicators & .261 \\
\hline ILO-index & Sum of ILO ratification implemented in each country in the period 1995-2005 & 5.297 \\
\hline hiperfprac & Index of high performance practices & 4.44 \\
\hline
\end{tabular}




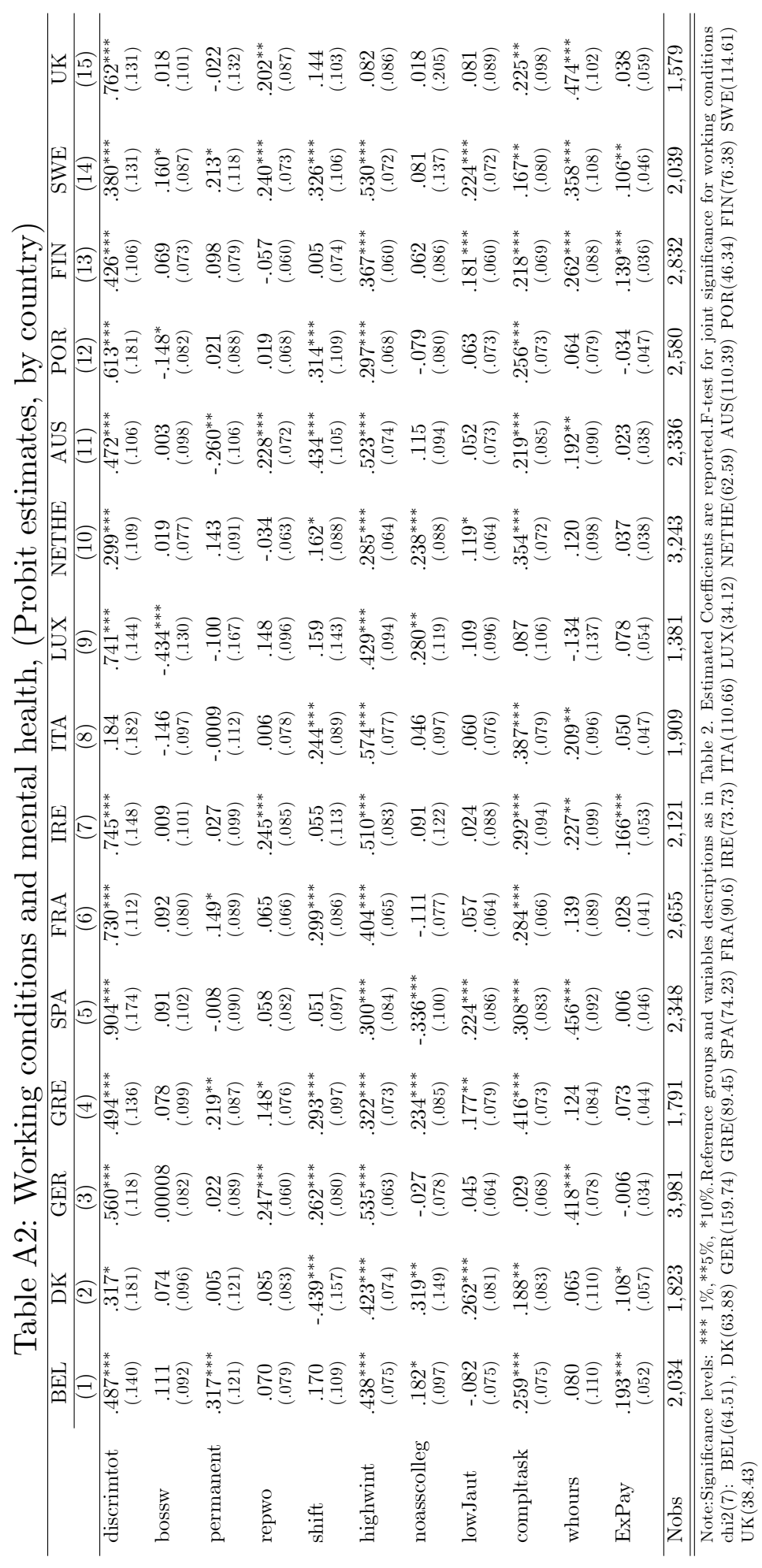

